\title{
Reduction Potentials of Material Waste Control Construction Methods on Building Sites in South-South, Nigeria
}

\author{
Timothy O. Adewuyi \\ Department of Building, University of Uyo \\ Faculty of Environmental Studies \\ Uyo, Akwa Ibom State \\ Nigeria
}

\begin{abstract}
Material waste reduction or minimisation reflection is essential in the studies of construction waste management, and it cannot be overstressed due to waste impact on project performance and outcomes. There are some construction methods and on-site management practices, termed in this study as material waste control construction methods (MWCCM), adopted from the manufacturing sector, that can curb the level of material waste generated on-site. The purpose of this study is to assess the extent of utilisation of MWCCM for alleviating material waste problems and domestically establish their potentials in reducing waste on-site. The correlation and relationship between MWCCM and material waste generated (MWG) on-site were determined. The study was carried out in the six States of SouthSouth geopolitical zone in Nigeria using a work study manual to collect data from the selected on-going projects in the study area. The descriptive research survey design approach was espoused for the study, and the data were analysed with canonical correlation. The study findings revealed that the squared correlation coefficient $\left(r^{2}\right)$ type effect size was 0.808, showing that the full model clarified a generous segment, about $81 \%$ of the variance shared between MWG and MWCCM. It demonstrates unique relationship between MWG and MWCCM with $F=2.918$ at $p<$ 0.05. Sequel to the results derived by this study, conclusions were reached that there are a significant correlations and relationship between MWG and MWCCM. Hence, MWCCM has great potential for reducing material waste on site. The study recommended MWCCM for use to assuage the menace of material waste generation on site, thereby improving the performance of project delivery.
\end{abstract}

Keywords: Extent of utilisation, Incentive practices, Material management, Material waste, Mechanisation of construction, Prefabrication.

\section{INTRODUCTION}

Studies on construction waste management cannot overemphasise the necessity of reducing material waste. Several authors have argued that there are avoidable material wastes, and there are unavoidable material wastes (Hasmori et al., 2020; Jayamathan \& Rameezdeen, 2014; Udeaja et al., 2013; Wahab \& Lawal, 2011; Formoso et al., 1999). It is now of common knowledge that there are a host of many causes of material waste as well as many approaches to reducing material waste generated on construction sites. Equally, there are several parties to a construction project who may contribute consciously or unconsciously to material waste generation on site. Furthermore, several studies (Hao et al., 2019; Ghisellini, Ripa \& Ulgiati, 2018; Won, Cheng \& Lee, 2016; Rocha \& Sattler, 2009) have revealed various effects of material wastes on project performance and project outcomes. Some other studies examined the effects of the varying degree of construction material waste generated on the construction industry's image, which amounts to economic, environmental, and social deprivations (Bovea \& Powell, 2016; Simion et al., 2013; Ortiz, Pasqualino \& Castells, 2010). These effects are summarily described as unsustainable practices (Yuan, 2013). Studies 
on construction waste reduction focus on reducing the impact of waste on the environment and promoting sustainable development of the construction industry (Liu, Yi, \& Wang, 2020). Adewuyi and Odesola (2015) revealed that the issue of material waste generation is complicated in the Nigerian construction industry. The study showed that the level of material waste generated on a project is attributable to many factors which are of many functions.

Nonetheless, there are some construction methods and on-site management practices that can be adopted from the manufacturing sector or usually employed on-site to curb the level of material waste. The idea of adopting the implementation of such manufacturing processes into construction was alluded to by Nduka et al. (2019), who asserted that the practice had gained popularity as new methods of construction. Such construction methods include material management practices, prefabrication (offsite construction, industrialised buildings, modern method of construction), mechanisation of production, incentive programme, automation, robotics, reproduction and a host of others (Zhang et al., 2018; Kamaruddin et al., 2018; Li et al., 2014a; Yuan et al., 2012; Pan et al., 2008; Tam \& Tam, 2008). These construction methods, no doubt, enhance material waste control and contribute significantly to waste reduction; hence, the developed and some developing countries practise their usage, but their extent of utilisation is not known in the Nigerian construction industry. The study of potentials of the material waste control construction methods (MWCCM) is lacking among local studies. There is a paucity of local literature on the use of incentive techniques to control the level of waste on-site. Akinkurolere and Franklin (2005) identified the incentive variables as part of the results of their study but did not research further into the usage. Therefore, the question is: Are the stakeholders in the Nigerian construction industry aware of the purpose of introducing these control methods to the practices of construction? If they do, to what extent have these methods been embraced and practiced? What is the magnitude of the potentials of the methods in reducing material waste on-site?

The relationship between the extent of utilisation of material management practices and the level of material waste generation was vividly captured in Adewuyi and Oladokun (2015), revealing that as the extent of utilisation of material management practices increases on-site, the level of material waste generated on-site reduces and vice versa. It follows then to affirm that material and site management functions can significantly minimise the level of waste generation on-site (Ajayi et al., 2017). Akinkurolere and Franklin (2005) argued that material handling and transportation of materials are mostly manually operated in the Nigerian construction industry and associated this with the high level of material waste in the industry. The study suggested that an increase in the level of mechanisation employed in construction operations could reduce the level of material waste generated (Zhang et al., 2018; Kamaruddin et al., 2018).

There are plethora pieces of literature to date on the reduction of material waste on-site through prefabrication of building elements (Zhang et al., 2018; Li et al., 2014a \& 2014b; Jaillon et al., 2009; Tam et al., 2006 \& 2007). In the Hong Kong construction industry, prefabrication is fully embraced, and most of the stakeholders appreciate its adoption. Incentive reward programmes have also been reported to effectively reduce the amount of material waste on-site (Liska \& Snell, 1992; Li, Chen \& Wong, 2003). In Nigeria, most construction site is not implementing any of the known contemporary approaches to waste minimisation consciously, resulting in wastes being generated uncontrollably. It is pertinent, therefore, to assess the extent of utilisation of these material waste control construction methods (MWCCM) for alleviating material waste problems, and domestically establish their potentials in reducing waste on-site. The inclusive aim of this research is to analyse MWCCM with an effort to pinpoint their efficacies and approaches for enhancing the effectiveness of waste reduction.

This study, therefore, is set to fulfil the following objectives:

i. $\quad$ Determining the extent of utilisation of selected MWCCM on building sites in each State of the study area;

ii. Evaluating the waste reduction potentials of MWCCM on the level of material waste generated on building sites in the study area.

Two hypotheses were employed to determine the correlation between MWCCM and material waste generation on-site (MWG) and to estimate the waste reduction potential of the selected MWCCM on material waste generation on-site (MWG).

$\mathrm{Ho}_{1}$ : There is no significant correlation between MWCCM and (MWG), and

$\mathrm{Ho}_{2}$ : The relationship between MWG and MWCCM is not significant. 


\section{REVIEW OF RELEVANT LITERATURE}

This study perceives MWCCM as the various strategies adopted from manufacturing industries to curb the generation of material wastes on construction sites. For example, materials management is a production strategy used in the manufacturing industries to control and monitor the use and movement of materials and to curb wastages. Mechanisation limits the incidence of material waste by reducing the volume of labour-intensive construction activities. For instance, activities such as transportation, packing, and stacking of blocks can be done mechanically instead of employing the use of wheelbarrow with labour operatives. Prefabrication transfers the stages of construction projects from the field (on-site) to an offsite production facility and has been identified as a solution to reducing waste arising during design and construction phases (Tam et al., 2006; Jaillon, Poon \& Chiang, 2009). The incentive reward programme (IRP) is viewed as an on-site material management system using incentive methods to control and reduce construction material wastes ( $\mathrm{Li}$, Chen \& Wong, 2003). The IRP is designed to encourage construction workers, who are directly involved in producing construction waste, in reducing waste by rewarding them based on the amounts and values of the materials they save. The MWCCM is discussed in the following stanzas.

\subsection{Prefabrication}

There are three significant categories of prefabrication in use in the production of various types of building components in the construction industry. These include i) Semi-prefabrication involves the production of nonstructural elements, which include facades, curtain walls, lost-form systems, and drywall systems; ii) Comprehensive prefabrication covers structural components like staircases, slabs, columns, and beams. Most comprehensive prefabrication is pre-finished in a fabrication yard before installation, and iii) Modular building is fully finished offsite as a 'one-stop' system (Tam, Tam \& Ng, 2007). Similarly, Poon, Yu and Ng (2001) and Li et al. (2014b), based on Hong Kong pattern, classified prefabricated elements into three as non-structural elements, structural elements, and volumetric elements. The non-structural elements were categorised under three main areas i) Facades units, examples of which are most commonly used in the Hong Kong construction industry which is pre-finished before installation; ii) Drywalls which are mainly used as partition walls where subsequent skim coat with painting is required; and iii) Cooking benches. However, Li et al. (2014a) and Goodier and Gibb (2007) presented prefabrication, as modern technology of building construction, in four stages or levels: (1) component manufacturing and sub-assembly; (2) nonvolumetric pre-assembly; (3) volumetric pre-assembly; and (4) whole buildings that refer to pre-assembled volumetric units.

It has been reported that some previous studies found that waste reduction propensity of prefabrication and modular construction can result in 52\% and $84.7 \%$ waste reduction correspondingly (Ajayi et al., 2015). Prefabrication ensures that building elements are manufactured offsite, assembled on-site, while other waste-originating parameters such as materials handling, inadequate storage, including design changes, have been eliminated. Tam et al. (2006) investigated the effectiveness of prefabrication in terms of waste reduction in replacing traditional wet-trade practices and examined the factors that help minimise construction wastes by the adoption of prefabrication. The study showed that timber formwork used for in-situ concrete casting enjoys the highest potential in waste reduction with an average avoidable wastage level of 58.2 percent. This study's result was corroborated in Nigeria by the study of Ogunde $e t$ al. (2016). The use of a drywall system (made of lightweight concrete) can reduce the wastage on bricklaying. The use of precast slab and staircase with the elimination of in-situ screeding can make some contribution to waste reduction. Jaillon, Poon and Chiang (2009) administered questionnaires to 84 experienced professionals in Hong Kong to evaluate the construction waste reduction level by employing the prefabrication method. The results revealed that the reduction of construction waste is one of the significant benefits of adopting prefabrication compared with conventional in-situ construction. The average level of waste reduction was about 52 percent. The study inferred that broader use of prefabrication could considerably reduce construction waste generation and alleviate the burdens associated with its management.

According to Tam, Tam and $\mathrm{Ng}$ (2007), six categories of prerequisites are necessary to implement prefabrication successfully: i) centralisation of production; ii) mass production; iii) standardisation; iv) specialisation; v) active organisation, and vi) integration. The study identified twenty-four characteristics of prefabrication, based on the previous literature. These include standardisation, adoption at the design stage, repetition, contractor's experience, dimensional coordination, client's requirements, mass production, the economics of scale, construction costs, production continuity, environmentally friendly, logistics, contract arrangement, steady supply of elements, pre- 
assembly, fast-tracking, safety, tolerances, less risky, government policy, interchangeability, predictability, regulations, and aesthetics (Tam, Tam \& Ng, 2007). Jaillon, Poon and Chiang (2009) considered ten factors as a barrier to the adoption of prefabrication in Hong Kong. The factors include conflict with the traditional design process, conflict with traditional construction practice, the need of specification change, lack of standard components, lack of skilled labour, lack of hoisting equipment capacity, lack of on-site cast yard area, lack of support from client, high overall cost, and lack of government incentive, technology, and availability of human resources. These impediments were corroborated by the studies of Zhang et al. (2018) who established that inflexible design change, lack of storage space on site, long lead-in time, long design time, high initial cost and high total cost were the most significant obstacles to the prefabrication of building elements.

\subsection{Material Management in Construction}

Materials used for construction comprise a significant cost part in any development venture. The total expenses on materials might be between 50 to 70 percent or a more considerable amount of the actual expense of project development (Karoriya \& Pandey, 2018; Albert, Shakantu \& Ibrahim, 2018), although the manufactured cost might be a minor piece of the aggregated cost, most likely under 20 to 30 percent (Perdomo, 2004). The vast increases of development in material waste minimisation recognised by various researchers are said to incorporate money related, social, natural, improvement of contractor and subcontractor worker's image, higher productivity, development time reserve funds, and wellbeing on building locales (Jayamathan \& Rameezdeen, 2014). In any case, lack of planning and control of materials, unavailability of materials when required, poor identification of materials, twofold handling and inadequate storage cause deprivations in labour efficiency, material wastage, and in general construction duration deferrals are some of huge factors that can inadvertently increase the overall costs of a construction project. The objective of each organisation is to make a profit. It explains the reason for the organisation's survival, and outlay ought not to surpass input costs, yet to remember the client's requirements. Effective management of materials can decrease expenditures by preventing the amount of material waste produced and contribute significantly to the success of the project.

Deficiencies in material management could precipitate material waste over the span of project development (Patil \& Pataskar, 2013). However, a viable material management framework can bring numerous advantages to an organisation. Among these advantages are decreased in the general expenses on materials, better treatment of materials, decrease in copied orders. Some other advantages are the availability of materials when required and the amounts required, enhancements in labour efficiency, upgrades in venture plan, quality control, better field material control, better relations with suppliers, a decrease of surplus materials, decrease of capacity of materials on location, work investment funds, stock decrease, buy reserve funds and better income the board. Past studies by Albert, Shakantu and Ibrahim (2018) showed that the main influences of effective materials management practices include materials' cost reduction, better quality control, efficient project site material control, effective material handling, adequate storage of materials on site, productivity improvements and avoidance of time overruns. It has been contended that it is difficult to dispose of all wastage completely (Hasmori et al., 2020; Jayamathan \& Rameezdeen, 2014). The worry ought to be how rehearses in the local industry can figure out minimisation of wastes, particularly in Nigeria, where industrialized structure methods have not been considerably grasped (Muleya \& Kamalondo, 2017).

According to Caldas et al. (2015), effective material management in the construction project settings calls for an approach that covers a wide range of functions such as material processing, purchasing, inventory management, storage and collection, handling and transport, processing and measurement, and the disposal of surpluses. The functions associated with the material asset management system are identified to include production and control, procurement, inventory planning, handling of materials, distribution, cost management, inventory/collection/loading, and transport (Sadiwala \& Sadiwala, 2007). Purchasing and procurement include the business of collecting materials to be used in those services.

The primary function of purchase and procurement is to obtain materials at the lowest possible cost, without sacrificing quality requirements (Patil \& Pataskar, 2013). Expediting is monitored by suppliers to ensure the timely delivery of purchased materials. Inventory planning, which is an essential function of inventory management, is closely linked to project planning and management. Both of these services work together to build a system for the purchase and storage of construction materials. It includes providing the required materials of good quality at the right prices from the right sources at the right time. 
Additionally, it also includes planning construction materials, including identification materials, size calculations, specification definitions, forecasting requirements, finding procurement sources, reviewing approved materials, designing materials, developing procurement ideas, and managing the flow of material until the construction work is connected. In other words, the purpose of the facilities is to purchase supplies for the days they need them, storage facilities, and handling requirements. The primary function of handling applications is to control the flow of materials in the organisation. The manager should ensure that the costs associated with the handling are kept to a minimum. In controlling the inventory, the manager has to make sure that the costs to purchase the materials are kept to a minimum. Inventory management deals with the availability of resources. Transportation involves the use of the safest economical methods to transport materials to the place where they are needed. The overall success of resource management practices is to ensure effective management and flow of resources (Arijeloye \& Akinradewo, 2016; Patil \& Pataskar, 2013; Sadiwala \& Sadiwala, 2007).

\subsection{Mechanisation/Automation of Construction}

Mechanisation is the process of shifting from working exclusively or basically by the manual method to using machines. Lebedev and Vorob'ev (2010) define mechanisation of production as the replacement of manual implements of labour in sectors of material production or labour processes with machines and mechanisms using various types of power and traction for their operation. The construction projects are becoming more challenging and complex in construction, and delay of projects would arise if the conventional construction method is used. There are many motivators of construction mechanisation, one of which is the reduction of construction-site waste. Brick has not changed from the literal placing of brick on brick, but masonry technology has been dramatically transformed. Motorised wheelbarrows and mortar mixers, sophisticated scaffolding systems, and forklift trucks now assist the bricklayer. Added to the list of existing innovations is the possibility of robotic bricklaying, and automated prototypes for masonry construction already exist.

The construction equipment embraces a diversity of machineries such as forklifts, dump trucks, vibratory compactors, hydraulic excavators, tippers, backhoe loaders, wheel loaders, bulldozers, graders, pavers, asphalt mix plants, cranes, dozers, off-highway dumpers, drills, scrapers, motor graders, rope shovels and a host of others. The mechanisation of production also covers the sphere of mental labour. Its primary goals are to raise labour productivity and free humans from heavy, labour-intensive, and fatiguing operations, which characterised Nigerian construction industry (Ogundipe, 2017). Automation of construction advances balanced and prudent utilisation of crude and processed materials, and energy, decreases prime expense and improves of item quality. Notwithstanding the improvement and substitution of equipment and production methods, automation is firmly connected to an ascent in the degree of labourers' aptitudes and the utilisation of strategies for logical association of work. Automation of construction is one of the principal roads to specialised advancement; it guarantees the improvement of profitable powers and fills in as the material base for raising the productivity of public construction, which is being created by rigorous techniques. A widely held perception subsisted in the studies of Sharmila, Devadoss and Matthew (2018) that construction mechanisation occasioned the reduction of material waste.

\subsection{Incentives Practices}

Incentive alludes to any factor which might be financial or not that empowers or inspires a specific game-plan or considers a purpose behind inclining toward one decision to the other options (Khan, 1993). Incentive policies for reducing the generation of construction waste can be implemented both by the individual organisation or the government. Akinade et al. (2018) observed that incentives for minimising construction waste could engender participation of stakeholders in construction waste reduction management initiatives. Liu, Yi and Wang (2020) opined that waste that is problematic to avoid at the source could be successfully treated through incentive policies, with an apparent long-term impact. The desire of most firms to be increasingly productive in the utilisation of labour or workforce has prompted the use of money related incentives. However, there are different types of remunerations and discipline for labourers' performance (Nelson, 1994). For instance, the utilisation of a unique motivation programme has been accounted for by Liskas and Snell (1992) and Olomolaiye, Jayawardane and Harris (1998). Sanders and Thompson (1999) demonstrated that those organisations that keep their programme straightforward with the primary target of the programme at the top of the priority list are believed to be effective. According to Saka and Ajayi (2010), incentive schemes may be categorised into three - semi-financial, non-financial, financial, and incentive schemes. 
Financial incentives scheme: Money related motivation scheme depends on cost intentions in its implementation. The workers are motivated to work shrewder and keener with the expectation of getting financial rewards far beyond their regular pay. The financial incentive has been proved to be effective in improving work quality and reducing project time and cost (Laufer \& Moore, 1983). Saka and Ajayi (2010) attributed the level of productivity attained in an organisation to money related motivations. Workers might be lured by the likelihood of additional income for more considerable effort, particularly in Nigeria, where the regular pay is low and unpredictable. However, Olomolaiye (1990) cautioned that the financial scheme might be counterproductive. There are many types of financial incentive schemes, which include Measured Day Work, Simple Piece Work, Geared Incentive Scheme, and Group-Incentive Scheme, Profit Sharing, Premium Bonus.

Non-Financial incentives: Motivations of this sort depend on raising a worker's feeling of fulfilment in their work. It depends on management's acknowledgment that a worker's work is significant to the business overall, and giving employees the proclivity that the venture embraced is intrinsically valuable (Liska \& Snell, 1992). For the most part, labourers' accomplishment in expanding efficiency ought to be fortified quickly by remunerations, which are termed extrinsic motivation, like cash, yet besides improved acknowledgment, contribution in strategy plan, and learning factors (Sauer, Rodgers \& Becker, 2018). Olomolaiye (1990) reckoned the different non-money related motivating forces as associations with peers, wellbeing programme, the work itself, cooperation of work and dynamic, proper supervision, promotion, thought-provoking task, professional stability, bonus, overtime and picking co-workers.

Semi-financial incentive: This sort of motivation lies between the two boundaries, and it has the qualities of both money related and non-monetary impetuses. Such advantages are, for the most part, extended to salaried staff whose employment opportunities are trying to gauge in a rough beneficial term. They may include benefits, for example, wellbeing plan, sparing plan, housing, site assistance arrangement, and pension plan. It is commonly acknowledged that projects joining components of both monetary and mental motivating forces are those that produce the most reliably agreeable outcomes. The general load of either segment inside a particular programme will rely upon organisation objectives, existing representative mentalities, and administrative capacities at the hour of a programme's usage (Liska \& Snell, 1992).

\subsection{Incentive reward programme}

The incentive reward programme provides a useful quantitative analysis and control method for the project manager to manage on-site materials, and to motivate workers to reduce material waste. Workers are executors of construction operations. Site surveys show that workers' attitudes toward construction operations and materials can make a significant difference in the amount of construction waste generated (Poon \& Ng, 1999). Without careful control and rewarding systems, construction workers may become careless in handling construction materials. As a result, reusable materials such as reinforcement bars, half-bags of cement, nails, timber pieces, and some other construction materials are often thrown away around the sites

The skill and attitude of workers are the main factors affecting the amounts of waste produced by workers (Pilcher, 1992). Between these two factors, workers' attitude toward their work, including their enthusiasm and collectivism, is the most important in terms of waste generation. In other words, if workers do not take care of what they are doing, then more materials will be wasted. So, it is crucial to establish an on-site construction material management system to encourage construction workers to handle materials carefully and efficiently and to enhance their enthusiasm and collectivism by rewarding them for their excellent performances for saving materials through reducing operational mistakes, returning unused materials for reuse or recycle. Additionally, the attitude and experience of contractors or subcontractors towards waste management have an impact on the amount of waste generated on-site.

\section{RESEARCH METHODOLOGY}

The study was carried out in the six States of South-South geopolitical zone in Nigeria and the total population of the study comprised of thirty-six (36) on-going projects in the study area. A descriptive research survey design approach was espoused for this study using the project work study manual as the research instrument. The material waste data collection manual used in this study was purposefully designed in conformity with the previously used one by Adewuyi (2012). The work study manual contained inquisitional phrases designed to collect information on the work processes and work content of the selected materials for this study, which in turn were used to obtain data on the magnitude of the waste involved in the construction operations. The second part focused on the use of MWCCM, 
namely: material management approach, prefabrication, incentive reward, and level of mechanisation on site. The resident consultants on the projects, and their counterparts in the employment of the contractors, were co-opted into the study to supply some vital information about the management of the project and materials. The co-opted professionals were to indicate either "used" or "not used" in the research instrument meant to monitor the extent of utilisation of each of the MWCCM employed on the site.

Thirty-two (32) variables were identified for material management practices, which were categorised into seven groups, namely: Material planning, Purchasing, Transportation and handling, Store keeping, Warehousing, Record keeping, and Disposal of surplus materials. To enable the correlation between the levels of material waste generated on each of the selected sites with the corresponding level of material management practices employed, the extent of utilisation of material management based on the overall variables assessed by this study were calculated using the expression in Equation 1. This was calculated as the ratio of the number of the practices used in a given site to the total number of material management variables observed by this study.

$$
M_{o}=\frac{m_{t}}{v}
$$

where:

$\mathrm{M}_{\mathrm{o}}$ is the overall extent of utilisation of material management in a given site,

$m_{t}$ is the total number of variables used on the given site, and

$v$ is the total number of all the variables observed in the study $(v=32)$.

Secondly, the essential activities during the work processes of the five building materials selected for the study were included in the research instrument to ascertain whether machines were employed during the work processes of the construction activities involving the use of the selected materials or were manually executed. The mechanisation of the work process contains nineteen (19) variables, which were categorised into five groups according to the work processes assessed, namely: concreting, blockwork, steel reinforcement, timber (formwork), and tiling. This is essential because it has been reported in the literature that more wastes were generated on sites where work processes are manually carried out than when mechanical devices are employed (Zhang et al., 2018; Tsai et al., 2013; Akinkurolere \& Franklin, 2005).

Idoro (2011) stated that the level of utilisation of machines for a construction project could be clarified in two ways: the number of plant and equipment engaged or the number of activities executed by plant and equipment in an operation. The latter explanation was adopted for this study for calculating the level of mechanisation because construction operations involve several tasks or a series of activities. The extent of utilisation was derived by Equation 2 for every site studied and correlated with the level of material waste generated on the given site.

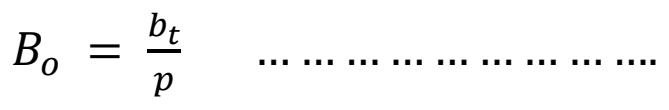

where:

$\mathrm{B}_{\mathrm{o}}$ is the extent of utilisation of machines in a given site;

$b_{t}$ is the total number of variables used on the given site, and

$p$ is the total number of all the mechanisation variables observed in the study $(p=19)$.

Thirdly, ten (10) items of incentive reward practices for curbing material waste on-site were identified through literature and adopted for this study. The use of these incentive practices are strategies of encouraging operatives on construction sites to ensure that materials are handled, transported, and appropriately utilised to ensure that avoidable material wastes are not generated on-site. The extent of utilisation of incentive was calculated as the ratio of the total number of the practices adopted on a given site to the total number of variables assessed by this study, as expressed in Equation 3. The extent of utilisation of incentive practices, Ro, is correlated with the level of waste generated on-site.

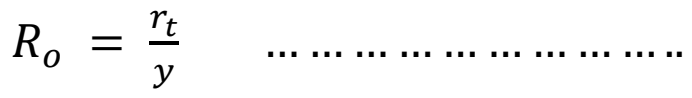

where:

$\mathrm{R}_{\mathrm{o}}$ is the extent of utilisation of incentive practices in a given site,

$r_{t}$ is the total number of variables used on the given site, and 
$y$ is the total number of all the incentive variables observed in the study $(y=10)$.

Lastly, seven building elements that can be prefabricated for purpose of controlling material waste were used as variables for prefabrication practices. These elements include columns, beam/lintel, non-bearing wall, lift shaft, stairs, slab, and partition walls. The research instrument was used to collect data on whether the listed seven building elements involving concrete works were prefabricated or cast in-situ on the thirty-six (36) building sites selected for work study.

The work study approach was used to determine the level of material waste generated on-site with the help of research assistants. This is done by monitoring the daily activities of the usage of materials selected for the study in each of the sites covered by the study. This is mainly to collect all the necessary data for the study. Equation 4 gives the formula used in calculating the percentage of material waste generated on-site. The extent of material waste generated was achieved by recording the initial quantities of materials started with for the day's construction operation and the leftover (final) quantities at the end of the day's work. It gives the basis for measuring the volume of materials consumed for the day's work. For the selected materials, the magnitudes of wastes were measured for concrete and reinforcement by volume and weight, respectively, while the area was used in measuring blockwork, formwork, and tiling. Additionally, an MS Excel template was created through which all the calculations for theoretical quantities of executed work were implemented. The theoretical quantities were achieved with the use of measured dimensions as performed by licensed projects' Quantity Surveyors with cognate years of experience. The obtained theoretical quantity was deducted from the actual quantity consumed on-site to determine the magnitude of material waste generated for every construction operation carried out for the selected studied materials.

Finally, the field data were assessed for the extent and correlational impacts utilising canonical relationship examination. Canonical correlation investigates the connection between two arrangements of factors with numerous builds. It makes separate multivariate for examination utilising numerous needy factors in this way representing superfluous elements not estimated straightforwardly by an investigation. The utilisation of this canonical analysis has increased diffused applications in development research, including Antonio et al. (2013) and Wong et al. (2015). In the separate examinations, numerous tests are utilised for translation of causal relationships, yet three of the related tests are well known across the construction industry field. The tests include: the multivariate test of significance, Eigenvalues, and correlations; and dimension reduction analysis; and this research embraced these tests. The hypothesis was tested with two head measures, the basic p-value and the extent of the squared canonical coefficient $\left(\mathrm{R}^{2} \mathrm{c}\right.$ ) (Sherry and Henson, 2005) were embraced. As per Sherry and Henson (2005), $\mathrm{R}^{2} \mathrm{c}$ between 45-100\% shows higher utility worth and are acknowledged, while $0-45 \%$ are dismissed for having low utility worth. Utilising the pvalue, $\mathrm{H}_{0}$ is dismissed with $\mathrm{p}<0.05$; and acknowledged $\mathrm{H}_{0}$ if $\mathrm{p}>0.05$.

\section{RESULTS AND DISCUSSION OF FINDINGS}

The methods used in the analysis of the data collected and testing the research hypotheses were descriptive and inferential statistics, including the use of Canonical Correlation. The extent of utilisation of each MWCCM was carried out based on the respective mathematical expression explained in the research methodology stanza. The results of the analysis are explicated in order as follows:

\subsection{The Extent of Utilisation of Material Management}

The extent of utilisation of the thirty-two (32) selected variables for material management practices was calculated, and the result is presented in Table 1. The results of the analyses are discussed according to the group of the practices. Material planning group: The examination, as presented in Table 1, reveals insight into significance appended to every one of the factors of material management practices and, consequently, the use. Estimating amounts of material required (MP2), monitoring the flow of materials till the associated development work is finished (MP9), and identifying materials (MP1) ranked in the first three positions in the material planning group with a level of utilisation estimations of 1.00, 0.97 and 0.94 separately. In all actuality, the nine recorded factors of material planning are required to rank successively from MP1 to MP9, be that as it may, the outcome in Table 1 depicts the genuine utilisation by the classifications of firms researched.

This result aligned with the findings of Arijeloye and Akinradewo (2016) that material planning is one of the most practiced activities in the construction ventures in Ondo State in Nigeria. Patil and Pataskar (2013) discovered that there is a deviation from the planned cost to an increase in the actual cost of material among the projects surveyed in 
India with the conclusion that material procurement and the total project budget may be affected inversely in such scenario.

Table 1: Extent of Utilisation of Material Management Practices in South-South, Nigeria

\begin{tabular}{|c|c|c|c|c|}
\hline Code & Material Management Practices & $\mathbf{m}_{t}$ & $\mathbf{M}_{\mathbf{0}}$ & Rank \\
\hline & Material planning & & & \\
\hline MP2 & Estimating quantities & 36 & 1.00 & 1 \\
\hline MP9 & Monitoring flow of material till the associated & 35 & 097 & 2 \\
\hline MP1 & Identifying materials & 34 & 0.94 & 3 \\
\hline MP3 & Defining specifications & 25 & 0.69 & 4 \\
\hline MP5 & Locating sources for procurement & 25 & 0.69 & 4 \\
\hline MP6 & $\begin{array}{l}\text { Getting sample of materials approved by the client or } \\
\text { his representative }\end{array}$ & 20 & 0.56 & 6 \\
\hline MP4 & Forecasting requirements & 19 & 0.53 & 7 \\
\hline MP8 & Developing procurement plans & 12 & 0.33 & 8 \\
\hline MP7 & $\begin{array}{l}\text { Designing materials inventory } \\
\text { Purchasing }\end{array}$ & 8 & 0.22 & 9 \\
\hline P10 & Centralised purchasing & 26 & 0.72 & 1 \\
\hline P13 & Direct purchase from supplier & 26 & 0.72 & 1 \\
\hline P12 & Mixed purchasing & 23 & 0.64 & 3 \\
\hline P14 & Purchasing by contract & 11 & 0.31 & 4 \\
\hline \multirow[t]{2}{*}{ P11 } & Decentralised purchasing & 7 & 0.19 & 5 \\
\hline & Store-keeping & & & \\
\hline SK22 & Centralised system & 28 & 0.78 & 1 \\
\hline SK24 & Mixed system & 23 & 0.64 & 2 \\
\hline \multirow[t]{2}{*}{ SK23 } & Decentralised system & 3 & 0.08 & 3 \\
\hline & Warehousing & & & \\
\hline W26 & Pallets & 20 & 0.56 & 1 \\
\hline W27 & Containers & 17 & 0.47 & 2 \\
\hline \multirow[t]{2}{*}{ W25 } & Shelves or racks & 16 & 0.44 & 3 \\
\hline & Transportation and Handling & & & \\
\hline TH16 & Wheelbarrow & 31 & 0.86 & 1 \\
\hline TH15 & Manual & 24 & 0.67 & 2 \\
\hline TH17 & Dumper & 8 & 0.22 & 3 \\
\hline TH18 & Forklift & 7 & 0.19 & 4 \\
\hline TH19 & Cranes & 5 & 0.14 & 5 \\
\hline TH20 & Hoist & 5 & 0.14 & 5 \\
\hline \multirow[t]{2}{*}{ TH21 } & Conveyors & 4 & 0.11 & 7 \\
\hline & Record keeping & & & \\
\hline RK28 & Daily stock taking & 29 & 0.81 & 1 \\
\hline RK29 & Logbook & 17 & 0.47 & 2 \\
\hline \multirow[t]{2}{*}{ RK30 } & Stock card system & 7 & 0.19 & 3 \\
\hline & Disposal of surplus material & & & \\
\hline DM32 & Surplus materials are used for other projects & 31 & 0.86 & 1 \\
\hline DM31 & Surplus materials are returned to suppliers & 7 & 0.19 & 2 \\
\hline
\end{tabular}

Purchasing group: The second group of the material management practices comprises of the various methodologies or techniques received in purchasing the necessary materials for development works. Table 1 shows the synopsis of the 
investigation for all the States in South-South. Direct purchase from suppliers ranked in the primary situation in this group with the extent of utilisation value of 0.72 , demonstrating that the vast majority of the contractors purchase their materials straightforwardly in the open market. Centralised purchasing is also positioned in the primary situation with the extent of utilisation value of 0.72 , highlighting the qualities of any typical engineering or production department where one purchase department or its single authority is approved and made capable of making a wide range of purchases for all the departments. The findings of this study corroborated the results obtained by Arijeloye and Akinradewo (2016), revealing that the direct purchase of materials is one of the standard practices of contracting firms.

Storage system: On the material storage system, Table 1 shows that the extent of utilisation of a centralised system of storage among the organisations surveyed is 0.78 and positioned in the principal position in the group of the storage system. The mixed system, which is the utilisation of both centralised and decentralised frameworks, was ranked in the following position while the decentralised framework is positioned in the third position. It is essential among small and medium firms, even some large ones, to keep up a centralised store since the wastage of materials can be limited because of better store format, its control, and the security of materials. The outcome on the storage system is along these lines considered proper, given the size and kind of firms surveyed. Albert, Shankatu and Ibrahim (2018) canvassed adequate storage of materials on site while Nanaware and Shaharkar (2017) cautioned participants in the construction business of maintaining an equilibrium of inventory control system to minimise the wastage of materials which ultimately could save the cost of a project, and the use of economic order quantity (EOQ) which gives the results of the right quantity of orders at the right time and it avoids the delays in material supply, including avoidance of materials wastage.

Warehousing: The result in Table 1 shows that the method mostly adopted by the firms is the use of a pallet, probably combined with the use of containers as in the storage of materials like cement to prevent damage or ordinarily for blocks. Shelves and racks is least used in the storage of bulk materials, which may be the reason for its least rank in the group.

Transportation and handling group: The outcome shows that the extent of utilisation of wheelbarrow and manual handling of transporting materials within site and storage is pervasive among the surveyed construction firms. This could account for a high degree of waste reported in extant literature. Akinkurolere and Franklin (2005) reported that manual labour was more extensively employed in most of the construction firms they surveyed than the use of mechanised labour for material handling and operations. The extent of utilisation of mechanisation for transportation and handling of materials ranges from 0.22 for site dumper to 0.11 for conveyors, which appear to be extremely low, as shown in Table 1.

\subsection{Extent of Utilisation of Mechanisation}

The extent of utilisation of mechanisation variables were categorised into five groups of construction work processes, namely: concreting, blockwork, ironwork, formwork, and tiling work, as shown in Table 2. For the purpose of evaluation, the extent of utilisation of the variables in each of the work processes were computed and ranked.

The extent of utilisation of the practices in concreting work revealed that batching is the most common practice where mechanisation is employed. This could be a result of the possibility to purchase or hire a concrete mixer. Compacting concrete ranked in the second position suggesting that the small and medium firms surveyed can easily own or hire poker vibrators for compacting concrete. Transporting and placing of concrete ranked in the third and fourth positions, respectively, suggesting that mobile concrete mixer or site dumper/wheelbarrow is within reach of the surveyed firms, but the low value of the extent of utilisation of these practices suggest that they were not substantially practiced by the surveyed projects. The result in this study is similar to the study of Idoro (2011), where it was found that the level of use of mechanisation ranked in the second position in four variables among the six variables selected for concrete works in the study. Idoro (2011) concluded that the level of use of mechanisation for batching, mixing, transporting, and placing is $27 \%, 27 \%, 33 \%$, and $31 \%$, respectively. The low level of use of mechanisation in concrete work processes suggests that material waste generation on building sites may be high. The analysis of the level of mechanisation in ironwork (reinforcement) shows that cutting activities is the most common activity which enjoyed the use of a machine. Despite this favourable result, the extent of utilisation as shallow as only $26 \%$ of the surveyed firms used this practice. 
The extent of utilisation of mechanisation in blockwork activities ranked storage of blocks in the first position while horizontal transportation ranked second with the extent of utilisation of $42 \%$ and $31 \%$, respectively. In the timber formwork process, horizontal transportation ranked in the first position while vertical transportation ranked in the last position with the extent of utilisation of mechanisation of $33 \%$ and $25 \%$, respectively. Cutting to suitable shape during the laying of tiles ranked in the first position among the activities in the tiling work process followed by horizontal transportation in the second position. The storage activity is the least ranked activity among all the activities.

Table 2: Extent of Utilisation of Machines in South-South, Nigeria

\begin{tabular}{|c|c|c|c|c|}
\hline Code & Mechanisation Practices & $b_{t}$ & $\mathbf{B}_{\mathbf{o}}$ & $\mathbf{R}$ \\
\hline & Concreting Work Processes & & & \\
\hline $\mathrm{C} 1$ & Batching (i. e. measuring and mixing the materials) & 15 & 0.42 & 1 \\
\hline $\mathrm{C} 4$ & Compacting & 10 & 0.28 & 2 \\
\hline $\mathrm{C} 2$ & Transporting & 9 & 0.25 & 3 \\
\hline \multirow[t]{2}{*}{ C3 } & Placing & 8 & 0.22 & 4 \\
\hline & Reinforcement Work Processes & & & \\
\hline $\mathrm{R} 1$ & Cutting & 10 & 0.28 & 1 \\
\hline $\mathrm{R} 2$ & Transporting & 8 & 0.22 & 2 \\
\hline \multirow[t]{2}{*}{$\mathrm{R} 3$} & Fixing & 7 & 0.19 & 3 \\
\hline & Blockwork & & & \\
\hline B3 & Storage & 15 & 0.42 & 1 \\
\hline B2 & Horizontal transportation & 11 & 0.31 & 2 \\
\hline B4 & Cutting to suitable shape during laying & 10 & 0.28 & 3 \\
\hline \multirow[t]{2}{*}{ B1 } & Vertical transportation & 8 & 0.22 & 4 \\
\hline & Formwork & & & \\
\hline F4 & Cutting to suitable shape during laying & 12 & 0.33 & 1 \\
\hline $\mathrm{F} 2$ & Horizontal transportation & 10 & 0.28 & 2 \\
\hline F3 & Storage & 10 & 0.28 & 2 \\
\hline \multirow[t]{2}{*}{$\mathrm{F} 1$} & Vertical transportation & 9 & 0.25 & 4 \\
\hline & Tiling work & & & \\
\hline $\mathrm{T} 4$ & Cutting to suitable shape during laying & 12 & 0.33 & 1 \\
\hline $\mathrm{T} 2$ & Horizontal transportation & 10 & 0.28 & 2 \\
\hline $\mathrm{T} 1$ & Vertical transportation & 9 & 0.25 & 3 \\
\hline $\mathrm{T} 3$ & Storage & 8 & 0.22 & 4 \\
\hline
\end{tabular}

Generally, the result on utilisation of machines in this study shows that the same phenomenon held in Akinkurolere and Franklin (2005), where it was found that manual labour was extensively employed among the construction firms surveyed in the South-Western part of Nigeria. Ogundipe (2017) equally inveterate labour-intensive operations in the Nigeria construction industry. Furthermore, the result shows that the reduction of material waste generated on-site may not be realised among the construction firms except the present phenomenon is improved as noted by Jabar et al. (2018), Kamaruddin et al. (2018) and Idoro (2011), particularly in the South-South region of Nigeria. Alinaitwe, Mwakali and Hansson (2006) found that in Uganda, the use of machines on building sites was insignificant but affirmed that mechanisation of construction could reduce the cost of buildings by $30 \%$. This study, therefore, encourages contractors to adopt the use of machines as it has the benefits of saving labour, fast-tracking work, producing better quality works, and are economical in many cases, apart from being able to do what cannot be done manually.

\subsection{The extent of Utilisation of Prefabrication}

The extent of utilisation of prefabrication as an MWCCM was estimated with eight building elements selected as variables. The research assistants indicated whether prefabrication or in-situ method of construction was adopted at 
the site. The result of the extent of utilisation of the prefabrication of building elements among the surveyed projects is shown in Table 3.

Table 3: Extent of Utilisation of Prefabrication for Selected Building Elements in South-South, Nigeria

\begin{tabular}{lllll}
\hline Code & Prefabrication of Building Element & $\mathbf{g}_{\mathbf{t}}$ & $\mathbf{G}_{\mathbf{o}}$ & $\mathbf{R}$ \\
\hline P7 & Partition wall & 9 & 0.25 & 1 \\
P2 & Beam/Lintel & 8 & 0.22 & 2 \\
P3 & Bearing wall & 7 & 0.19 & 3 \\
P5 & Stairs & 7 & 0.19 & 3 \\
P6 & Slab & 7 & 0.19 & 3 \\
P1 & Column & 6 & 0.17 & 6 \\
P4 & Lift shaft & 0 & 0.00 & 7 \\
\hline
\end{tabular}

$\mathrm{N}=36$ (total number of sites observed); $\mathrm{G}_{\mathrm{o}}$ is the extent of utilisation of prefabrication; $\mathrm{g}_{\mathrm{t}}$ is the total number of the site where prefabrication was used for the given element; and $\mathrm{R}=$ Rank

The partitioning wall ranked in the first position among the prefabricated building elements with the extent of utilisation value of 0.25 , as shown in Table 3. Partition walls may take the form of curtain wall, panel walls, and perhaps the use of light-frame materials for partition. Beams or lintels ranked in the second position among the building elements attracting the use of the prefabricated element. This result is consistent with the findings of Ogunde et al. (2016) in the South-Western part of Nigeria (Lagos), where it was established that about $39.1 \%$ of professionals involved in the use of prefabricated building projects had used wall panels and slabs, beams, and columns. The low level of use of prefabricated elements for beam may be accounted for in the rigid connections required between beam and column (Wong, Hao \& Ho, 2005). The use of prefabricated elements for load-bearing walls, staircases, and slab ranked in the third position. The value is low since it is not often used without the availability of heavy construction equipment required for erection. Equally, the use of the prefabricated structural frame is not prevalent in the study area; hence most of the walls in structures more than two floors level are usually of non-loading walls. The use of prefabricated elements for staircases and slab ranked in the third rank with bearing types. The precast slabs are in the form of filigran slabs or filigran floors, which is a semi-prefabricated element. It acts as permanent formwork for insitu slab work; hence it reduces the use of formwork.

The precast columns ranked in the sixth position and can be fixed and grouted into prepared bases or by the use of friction grip bolts, depending on the design. Lift shaft is ranked in the last positions among the building elements in their extent of utilisation on site. These are practically non-existent in the study area or, at least, among the surveyed projects. Where it exists, it must have been installed on a sub-contractual arrangement for those firms. Summarily, prefabrication of building elements, as noted by Ogunde et al. (2016), have not been widely adopted in Nigeria as the findings of this study revealed as its use is limited to government client.

\subsection{The Extent of Utilisation of Incentive Practices}

The evaluation of the extent of utilisation of incentive practices was descriptively analysed using the expression in Equation 3, as explained in the methodology. The number of sites where each of the variables was practiced were recorded and expressed as a ratio of the number of sites observed. The results of the evaluation are presented in Table 4.

Using the right specifications ranked in the first position among the extent of utilisation of incentive practices, as shown in Table 4, with an extent of utilisation value of 0.83 . The use of the right specified materials goes with many benefits such as preventing rework resulting from the use of the wrong specification, getting the expected result at the first attempt, increased productivity, and rework due to workers' mistakes and reduces the cost of supervision. These benefits might account for the reason for the high value of utilisation of the practice among the surveyed projects and the adoption of the practice. Two practices, namely: increasing salary when deemed fit and incentive practice of regular payment of workers salary at the time due; and provision of medical care for workers in case of accidents; ranked in the second position with the extent of utilisation value of 0.61 as shown in Table 4 . These two practices are 
closely related. Delay in payment of salary or wages to workers encourages theft and vandalism on building sites because the workers will naturally exploit other ways of getting their needs met if their wages are delayed or denied.

Table 4: Extent of Utilisation of Incentive Practices in South-South, Nigeria

\begin{tabular}{|c|c|c|c|c|}
\hline Code & Incentive Practices & $r_{t}$ & $\mathbf{R}_{\mathbf{o}}$ & $\mathbf{R}$ \\
\hline v7 & Using the right specifications. & 30 & 0.83 & 1 \\
\hline $\mathrm{v} 4$ & $\begin{array}{l}\text { Regular payment of workers salary as time due and provision of medical } \\
\text { care for workers in case of an accident }\end{array}$ & 22 & 0.61 & 2 \\
\hline v5 & Increasing salary when deemed fit. & 22 & 0.61 & 2 \\
\hline v9 & $\begin{array}{l}\text { Good design, detailing, and erection practice all lead to waste } \\
\text { minimisation, these should be rewarded periodically in cash or kind. }\end{array}$ & 21 & 0.58 & 4 \\
\hline v10 & Avoid overloading trucks. & 19 & 0.53 & 5 \\
\hline v3 & Giving a bonus to workers. & 12 & 0.33 & 6 \\
\hline v6 & Promoting good handlers. & 12 & 0.33 & 6 \\
\hline $\mathrm{v} 2$ & Supervision and active monitoring by experts. & 11 & 0.31 & 8 \\
\hline v8 & Approving more overtime hours. & 10 & 0.28 & 9 \\
\hline v1 & Commendation of hardworking and careful workers in kind and cash & 5 & 0.14 & 10 \\
\hline
\end{tabular}

Good design, detailing, and erection practice ranked in the fourth position, which shows the level of supervisory efficiency or proficiency. This practice is peculiar to either resident consultants or contractor's supervisory staff. Avoiding overloading the trucks ranked in the fifth position, as shown in Table 4. Overloading trucks may result in an avoidable accident resulting in a waste of material. Promoting good handlers and giving bonuses to workers ranked in the sixth position with an extent of utilisation value of 0.33 . Supervision and active monitoring by experts ranked in the eighth position with an extent of utilisation of 0.31 .

The second to the last ranked practice (approving more overtime hours) has the extent of utilisation value of 0.28 while the least ranked incentive practice, commendation of hardworking and careful workers in kind and in cash, is scored 0.14. The last two practices scored low because the management of small and medium construction firms pay less attention to these practices. Negligence by site managers of the least rated practices may explain the reasons for site operatives' lukewarm, nonchalant, or lackadaisical attitude towards the proper management of material to curbing avoidable wastage. This can be substantiated with the views of Ajayi et al. (2017) that it is imperative for site managers and other project participants to appreciate the fundamental site management practices for stimulating waste minimisation in construction projects. Li, Chen and Wong (2003) reported an increase of $0.92 \%$ in the cost of material in a project in Hong Kong where a group-based incentive reward programme meant to reduce material waste was not implemented and in contrast, a savings of $0.76 \%$ on the same type of project with the implementation of incentive programme given a difference of $1.68 \%$ of the total cost of materials between the two projects. However, Liu, Yi, and Wang (2020) found that the path coefficient of government subsidy as an incentive policy for waste reduction is 0.52 , making it the measure with the least impact on construction waste reduction compared with the other measures. Therefore, the onus is on stakeholders in the Nigerian construction industry to incorporate incentive practices for conscious effort towards waste minimisation.

\subsection{Waste-Reduction Potentials of MWCCM}

An analysis involving four MWCCM methods as indicators of the five (5) selected types of material waste generated on sit using canonical correlation method was conducted to assess the multivariate shared correlation between the two variable sets [i.e., MWCCM and material waste generation (MWG)]. The investigation generated four canonical functions with squared correlations $\left(\mathrm{R}^{2} \mathrm{c}\right)$ of $0.685,0.257,0.155$, and 0.029 for each progressive function. All things considered, the full model was measurably vast utilising the Wilks' lambda $(\lambda)=0.192$ rule, $F(20,90.5)=2.918, p<$ 0.001 . Since Wilks' $\lambda$ expresses the change unexplained by the model, $1-\lambda$ yields the full model impact size in an $r^{2}$ (squared correlation coefficient) metric. Hence, for the arrangement of four accepted functions, the $\mathrm{r}^{2}$ type effect size was 0.808 , which shows that the full model clarified a generous segment, about $81 \%$, of the variance shared between 
the variable sets. It demonstrates the nearness of the correlation between the generated wastes and the technique for waste control (MWCCM). The symptomatic hypothesis $\left(\mathrm{Ho}_{1}\right)$ is, based on these revealings, rejected. The suggestion is that a unique relationship exists between MWG and MWCCM $(F=2.918$ with $\mathrm{p}<0.05)$. This induction is critical and acknowledged. The overall fitness of the accepted model for $\mathrm{Ho}_{1}$ is sufficient and proper. All the explained parameters are shown in Appendix.

The Eigen Value and Canonical Correlation value show the degree of the variates of the canonical roots (Sherry and Henson, 2005). It is utilised to decide the quality of essence or nonattendance of correlational connections. The outcome shows a positive correlation estimation of 0.827 with a clarified fluctuation of $79.572 \%$ and a high Eigenvalue of 2.177. This outcome strengthens two things: first, that accepted model created by a multivariate test is satisfactory. The second is that the dismissal of the suggestive theory $\left(\mathrm{Ho}_{1}\right)$ is suitable, and the tie is clarified by $79.57 \%$ of material waste methods (accepted roots).

The dimension reduction examination permits the researcher to test the hierarchal course of action of the functions for statistical noteworthiness. As noticed, the full model (Functions 1 to 4 ) was the main critical function. Functions 2 to 4,3 to 4 and 4 were not factually noteworthy, $\mathrm{F}(12,74.37)=1.274, \mathrm{p}=0.252, \mathrm{~F}(6,58)=1.003, \mathrm{p}=0.432$, and $\mathrm{F}(2$, $30)=0.44, p=0.648$, separately and didn't clarify measurably critical measure of shared difference between the variable sets.

According to Sherry and Henson (2005), every one of the derived functions needs to be evaluated for the reason that some of them may not explicate enough of the relationship between the variable sets to warrant interpretation, just like a puny or unwell defined factor in a factor analysis would be discarded. Moreover, the full model probably seems significant at the cumulative level, but an investigation of each function divulges each of them to be feeble and not interpretable in and of themselves. For instance, each function may not contribute much to the total solution, but the cumulative total solution may be statistically significant and perhaps noteworthy. In such cases, the interpretation of each function separately would be questionable. Therefore, based on the impacts for each function, just the first and the second functions were viewed as critical with regards to this investigation, with $68.52 \%$ and $25.7 \%$ of shared variance individually. Though the second function seems statistically insignificant with $p=0.252$, the percentage $(25.7 \%)$ of the shared variance it explained makes it approbative, considering the small sample size (36 cases) which may impact on statistical significance (Pallant, 2007). The other two functions just clarified 15.5\%, and 2.85\%, separately, of the rest of the change in the variable sets after the extraction of the earlier two functions.

Table 5 presents the standardized canonical function coefficients and structure coefficients for Functions 1 and 2. The squared structure coefficients were also given as well as the communalities $\left(h^{2}\right)$ across the two functions for each variable. Looking at the Function 1 coefficients, one sees that relevant criterion variables were primarily material management, incentive practices, and mechanisation, with prefabrication making secondary contributions to the synthetic criterion variable. The squared structure coefficients supported the conclusion. These material waste control approaches also tended to have more significant canonical function coefficients. A slight exception involved incentive practices, which had modest function coefficients but a significant structure coefficient.

Table 5: Canonical Solution for Utilising MWCCM Against Waste Generation on site

\begin{tabular}{llllllll}
\hline & \multicolumn{2}{l}{ Function 1 } & & \multicolumn{3}{c}{ Function 2 } & $\mathrm{h}^{2}(\%)$ \\
& Coeff. & $\mathrm{r}_{\mathrm{s}}$ & $\left(\mathrm{r}_{\mathrm{s}}\right)^{2}[\%]$ & Coeff. & $\mathrm{r}_{\mathrm{s}}$ & $\left(\mathrm{r}_{\mathrm{s}}\right)^{2}[\%]$ & \\
\hline Material Management & -0.470 & -0.845 & 71.43 & -0.747 & -0.401 & 16.05 & 87.48 \\
Mechanisation & -0.450 & -0.704 & 49.56 & 1.460 & 0.120 & 1.45 & 51.01 \\
Incentive & -0.185 & -0.761 & 57.93 & -0.796 & -0.312 & 9.72 & 67.65 \\
Prefabrication & 0.509 & 0.286 & 8.15 & -0.734 & -0.377 & 14.20 & 22.35 \\
$\mathrm{R}^{2} \mathrm{c}$ & & & 68.52 & & & 25.70 & \\
Concrete work & 0.640 & 0.811 & 65.70 & 1.181 & -0.143 & 2.06 & 67.76 \\
Blockkwork & 0.071 & 0.684 & 46.79 & -0.016 & -0.150 & 2.25 & 49.04 \\
Reinforcement & 0.301 & 0.683 & 46.65 & 0.546 & 0.170 & 2.89 & 49.54 \\
Timber formwork & -0.199 & 0.674 & 45.45 & -1.675 & -0.619 & 38.29 & 83.74 \\
Tiling work & 0.433 & 0.832 & 69.30 & -0.228 & -0.166 & 2.74 & 72.04 \\
\hline
\end{tabular}

Note. Structure coefficients $(r \mathrm{~s})$ greater than $|0.45|$ are underlined. Communality coefficients $\left(h^{2}\right)$ greater than $45 \%$ are underlined. Coeff. $=$ standardized canonical function coefficient; $r \mathrm{~s}=$ structure coefficient; $r^{2} \mathrm{~s}=$ squared structure coefficient; $h^{2}=$ communality coefficient. 
Furthermore, except for prefabrication, all of these variables' structure coefficients had the same sign, indicating that they were all positively related. Prefabrication was inversely related to the other waste control measures. Sequel to the results derived by this analysis, the second hypothesis $\left(\mathrm{H}_{02}\right)$ was rejected, and a conclusion was reached that there is a significant relationship between the MWCCM and MWG. Hence, MWCCM has great potentials for reducing material waste on site.

\section{CONCLUSIONS AND RECOMMENDATIONS}

The material waste problems might exacerbate the poor performance of construction projects unless participants in the construction industry make conscious and determined efforts. Some construction methods and on-site management practices, termed in this study as material waste control construction methods (MWCCM), which were adopted from the manufacturing sector, present the opportunities to curb the level of material waste generated on-site. The extent of utilisation of MWCCM (material management practices, prefabrication, mechanisation of construction, and incentive practices) was examined by this study and was found to be low. However, the correlation and relationship between MWCCM and material waste generated on site (MWG) pictured potential gains towards the reduction of material waste generation. Consequent to the results derived by this study, conclusions were reached that there is a significant correlation and relationship between MWG and MWCCM. Hence, MWCCM has great potential for reducing material wastes on site. Therefore, the impediments to the full implementation and practices of MWCCM by construction stakeholders need to be studied and highlighted to the benefits of enhanced performance of the construction industry in the study area. The study recommended MWCCM for use to assuage the menace of material waste generation on site, thereby improving the performance of project delivery.

\section{The Implication for Research, Practice, and Society}

The enhancement or adoption of MWCCM will help to reduce the level of material waste generated on-site and improve the image of the local construction industry. The reduction in the level of material waste generated will in turn, reduce the menace of cost overruns and other impacts of material waste generation on project outcomes, which has become a common feature of construction projects in Nigeria. Moreover, the knowledge of the potentials of the MWCCM will guide the construction stakeholders in the choice and decision on the approach or method to employ in reducing material waste on-site.

\section{REFERENCES}

[1]. Hasmori, M. F., Md Zin, A. F., Nagapan, S., Deraman, R., Abas, N., Yunus, R. and Klufallah, M. (2020). The On-site Waste Minimization Practices for Construction Waste. The 2nd Global Congress on Construction, IOP Conference Series: Materials Science and Engineering, 713, 1-11. https://doi.org/10.1088/1757$\underline{899 X / 713 / 1 / 012038}$

[2]. Jayamathan, J. and Rameezdeen, R. (2014). Influence of Labour Arrangement on Construction Material Waste Generation. Structural Survey, 32(2): 76-88. http://dx.doi.org/10.1108/SS-09-2012-0026

[3]. Udeaja, C., Ekundayo, D., Zhou, L., and Perera, S. (2013). Material Waste in the Construction Industry: A Review of the Legislative and Supply Chain Issues. In Richardson, A. (ed.), Reuse of Materials and Byproducts in Construction, Green Energy and Technology, 5-27. https://doi.org/10.1007/978-1-4471-53764_2.

[4]. Wahab, A. B. and Lawal, A. F. (2011). An Evaluation of Waste Control Measures in Construction Industry in Nigeria. African Journal of Environmental Science and Technology, 5(3), 246-254.

[5]. Formoso, C.T., Isatto, E.L., and Hirota, E. H. (1999). Method for Waste Control in the Building Industry. Proceedings of the Seventh Annual Conference of the International Group for Lean Construction (IGLC-7), University of California, Berkeley, CA, USA. 325-334.

[6]. Hao, J., Yuan, H., Liu, J., Chin, C. S. and Lu, W. (2019). A Model for Assessing the Economic Performance of Construction Waste Reduction. Journal of Cleaner Production, 232, 427-440.

https://doi.org/10.1016/j.jclepro.2019.05.348 
[7]. Ghisellini, P., Ripa, M. and Ulgiati, S. (2018). Exploring Environmental and Economic Costs and Benefits of a Circular Economy Approach to the Construction and Demolition Sector. A Literature Review. Journal of Cleaner Production, 178, 618-643. https://doi.org/10.1016/j.jclepro.2017.11.207.

[8]. Won, J., Cheng, J. C. and Lee, G. (2016). Quantification of Construction Waste Prevented by BIM-Based Design Validation: Case Studies in South Korea. Waste Management, 49, 170 - 180.

http://dx.doi.org/10.1016/j.wasman.2015.12.026

[9]. Rocha, C. G. and Sattler, M. A. (2009). A Discussion on the Reuse of Building Components in Brazil: An Analysis of Major Social, Economical and Legal Factors. Resources, Conservation and Recycling, 54(2), 104-112. https://doi.org/10.1016/j.resconrec.2009.07.004

[10]. Bovea, M. D. and Powell, J. C. (2016). Developments in Life Cycle Assessment Applied to Evaluate the Environmental Performance of Construction and Demolition Wastes. Waste Management, 50: 151-172. https://doi.org/10.1016/j.wasman.2016.01.036.

[11]. Simion, M. S., Ghinea, C., Maxineasa, S. G., Taranu, N., Bonoli, A. and Gavrilescu, M. (2013). Ecological Footprint Applied in the Assessment of Construction and Demolition Waste Integrated Management. Environmental Engineering and Management Journal, 12(4), 779-788.

https://doi.org/10.30638/eemj.2013.097

[12]. Ortiz, O., Pasqualino, J. C. and Castells, F. (2010). Environmental Performance of Construction Waste: Comparing Three Scenarios from a Case Study in Catalonia, Spain. Waste Management, 30(4), 646-654. https://doi.org/10.1016/j.wasman.2009.11.013.

[13]. Yuan, H. (2013). Key Indicators for Assessing the Effectiveness of Waste Management in Construction Projects. Ecological Indicators, 24, 476-484. https://doi.org/10.1016/j.ecolind.2012.07.022.

[14]. Liu, J., Yi, Y. and Wang, X. (2020). Exploring Factors Influencing Construction Waste Reduction: A Structural Equation Modeling Approach. Journal of Cleaner Production, https://doi.org/10.1016/j.jclepro.2020.123185.

[15]. Adewuyi, T. O. and Odesola, I. A. (2015). Factors Affecting Material Waste on Construction Sites in Nigeria. Journal of Engineering and Technology, 6(1), 82-99.

https://journal.utem.edu.my/index.php/jet/article/view/237

[16]. Nduka, D. O., Fagbenle, O. I., Ogunde, A. and Afolabi, A. (2019). Critical Success Factors (CSFs) Influencing the Implementation of Industrialized Building Systems (IBS) in Nigeria. Proceedings of 1st International Conference on Sustainable Infrastructural Development, IOP Conference Series: Materials Science and Engineering, 640, 1-11. http://doi.org/10.1088/1757-899X/640/1/012012

[17]. Zhang, W., Lee, M. W., Jaillon, L. and Poon, C. S. (2018). The Hindrance to Using Prefabrication in Hong Kong's Building Industry. Journal of Cleaner Production, 204, 70-81.

https://doi.org/10.1016/j.jclepro.2018.08.190.

[18]. Kamaruddin, S. S., Mohammad, M. F., Mahbub, R. and Ahmad, K. (2018). The Mechanisation and Automation of the IBS Construction Approach in Malaysia. Asian Journal of Environment-Behaviour Studies (ajE-Bs), 3(10), 167-177. https://doi.org/10.21834/aje-bs.v3i10.324.

[19]. Li, Z., Shen, G. Q. and Xue, X. (2014a). Critical Review of the Research on the Management of Prefabricated Construction. Habitat International, 43, 240-249. https://doi.org/10.1016/j.habitatint.2014.04.001

[20]. Yuan, H., Chini, A. R., Lu, Y. and Shen, L. (2012). A Dynamic Model for Assessing the Effects of Management Strategies on the Reduction of Construction and Demolition Waste. Waste Management, 32(3), 521-531. https://doi.org/10.1016/j.wasman.2011.11.006 
[21]. Pan, W., Gibb, A. G. F. and Dainty, A. R. J. (2008). Leading UK Housebuilders' Utilization of Offsite Construction Methods. Building Research and Information, 36(1), 56-67. http://dx.doi.org/10.1080/09613210701204013.

[22]. Tam, V. W. Y. and Tam, C. M. (2008): Waste Reduction Through Incentives: A Case Study. Building Research and Information, 36(1), 37-43. http://dx.doi.org/10.1080/09613210701417003.

[23]. Akinkurolere, O. O. and Franklin, S. O. (2005). Investigation into Waste Management on Construction Sites in South-Western Nigeria. American Journal of Applied Sciences, 2(5), 980 - 984.

[24]. Adewuyi, T. O. and Oladokun, M. G. (2015). Relationship between Material Management and Material Waste on Sites in Nigeria. Nigerian Journal of Construction Technology and Management, 13(1\&2), 1- 15.

[25]. Ajayi, S. O., Oyedele, L. O., Bilal, M., Akinade, O. O., Alaka, H. A. and Owolabi, H. A. (2017). Critical Management Practices Influencing On-Site Waste Minimization in Construction Projects. Waste Management, 59, 330-339. https://doi.org/10.1016/j.wasman.2016.10.040.

[26]. Li, Z., Shen, G. Q. and Alshawi, M. (2014b). Measuring the impact of prefabrication on construction waste reduction: An empirical study in China. Resources, Conservation and Recycling, 91, 27-39. https://doi.org/10.1016/j.resconrec.2014.07.013

[27]. Jaillon, L., Poon, C.S. and Chiang, Y.H. (2009). Quantifying the Waste Reduction Potential of using Prefabrication in Building Construction in Hong Kong. Waste Management, 29(1), 309-320.

https://doi.org/10.1016/j.wasman.2008.02.015

[28]. Tam, V. W. Y., Tam, C. M., Chan, J. K. W. and Ng, W. C. Y. (2006). Cutting Construction Wastes by Prefabrication. International Journal of Construction Management, 6(1): 15-25. https://doi.org/10.1080/15623599.2006.10773079

[29]. Tam, V. W. Y., Tam, C. M. and Ng, W. CY. (2007 ). On Prefabrication Implementation for Different Projects Types and Procurement Methods in Hong Kong. Journal of Engineering, Design and Technology, 5(1): 6880. https://doi.org/10.1108/17260530710746614

[30]. Liska, R. W. and Snell, B. (1992). Financial Incentive Programme for Average-Size Construction Firm. Journal of Construction Engineering and Management, 118(4), 667-676.

https://doi.org/10.1061/(ASCE)0733-9364(1992)118:4(667)

[31]. Li, H., Chen, Z. and Wong, C. T. C. (2003). Barcode Technology for an Incentive Reward Programme to Reduce Construction Wastes. Computer-Aided Civil and Infrastructure Engineering, 18(4), 313-324. https://doi.org/10.1111/1467-8667.00320

[32]. Poon, C. S., Yu. A. T. W. and Ng, L. H. (2001). On-site Sorting of Construction and Demolition Waste in Hong Kong. Resource, Conservation and Recycling, 32(2), 157- 172. https://doi.org/10.1016/S0921$\underline{3449(01) 00052-0}$

[33]. Goodier, C. and Gibb, A. (2007). Future Opportunities for Offsite in the UK. Construction Management and Economics, 25(6), 585-595. https://doi.org/10.1080/01446190601071821

[34]. Ajayi, S. O., Oyedele, L. O., Bilal, M., Akinade, O. O., Alaka, H. A., Owolabi, H. A., and Kadiri, K. O. (2015). Waste Effectiveness of the Construction Industry: Understanding the Impediments and Requisites for Improvements. Resources, Conservation and Recycling, 102, 101-112. https://doi.org/10.1016/j.resconrec.2015.06.001

[35]. Ogunde, A., Selekere, T. E., Joshua, O., Kukoyi, P. O. and Omuh, I. O. (2016). Prefabrication Method of Building Construction in Lagos State, Nigeria: Prospects and Challenges. International Journal of Engineering Technology and Computer Research (IJETCR), 4(1), 88-100. 
International Journal of Advances in Scientific Research and Engineering (ijasre), Vol 6 (8), August -2020

[36]. Karoriya, D. and Pandey, M. (2018). Efficient Techniques of Construction Material Management in Construction Projects. International Research Journal of Engineering and Technology (IRJET), 5(3), 11391142.

[37]. Albert, I., Shakantu, W. and Ibrahim, K. (2018). Impact of Materials Management Practices in the Nigerian Building Construction Industry. Journal of Construction Project Management and Innovation, 8(1), 1789 1796. https://hdl.handle.net/10520/EJC-10a4fa1750

[38]. Perdomo, J. L. (2004). A Framework for a Decision Support Model for Supply Chain Management in the Construction Industry. PhD Thesis, Faculty of the Virginia Polytechnic Institute and State University, Blacksburg, Virginia.

[39]. Patil, A. R. and Pataskar, S. V. (2013). Analyzing Material Management Techniques on Construction Project. International Journal of Engineering and Innovative Technology (IJEIT), 3(4), 96-100.

[40]. Muleya, F. and Kamalondo, H. (2017). An Investigation of Waste Management Practices in the Zambian Construction Industry. Journal of Building Construction and Planning Research, 5(1), 1-13.

[41]. Caldas, C. H., Menches, C. L., Reyes, P. M., Navarro, L., and Vargas, D. M. (2015). Materials Management Practices in the Construction Industry. Practice Periodical on Structural Design and Construction, 20(3), 04014039. https://doi.doi/10.1061/(ASCE)SC.1943-5576.0000238

[42]. Sadiwala, C. M. and Sadiwala, R. C. (2007). Materials and Financial Management. Daryaganj, New Delhi: New Age International Publishers Ltd, pp. 1 -237.

[43]. Arijeloye, B. T. and Akinradewo, F. O. (2016). Assessment of Materials Management on Building Projects in Ondo State, Nigeria. World Scientific News: An International Scientific Journal, 55, 168-185.

[44]. Lebedev, V, D. and Vorob'ev, D. P. (2010). The Great Soviet Encyclopaedia, 3rd Edition. The Gale Group Incorporated. http://encyclopedia2.thefreedictionary.com/Mechanisation+of+Production. Retrieved August 3, 2020.

[45]. Ogundipe, K. E. (2017). Safety Practices and Workers Performance on Construction Sites in Lagos State, Nigeria. Unpublished M.Sc. Dissertation, Department of Building Technology, Covenant University Ota, Ogun State, Nigeria

[46]. Sharmila, S., Devadoss, R. S. and Mathew, F. (2018). Impact of Mechanisation in Construction Projects in India. International Journal of Civil Engineering and Technology (IJCIET), 9(13), 1998-2008.

[47]. Khan, M. (1993). Methods of Motivating for Increased Productivity. Journal of Management in Engineering, 9(2): 148-156. https://doi.org/10.1061/(ASCE)9742-597X(1993)9:2(148)

[48]. Akinade, O. O., Oyedele, L. O., Ajayi, S. O., Bilal, M., Alaka, H. A., Owolabi, H. A., and Arawomo, O. O. (2018). Designing Out Construction Waste Using BIM Technology: Stakeholders' Expectations for Industry Deployment. Journal of Cleaner Production, 180, 375-385. https://doi.org/10.1016/j.jclepro.2018.01.022

[49]. Nelson, B. (1994). 1001 Ways to Reward Employees. New York: Workman Publishing, p. 2.

[50]. Olomolaiye, P. O., Jayawardane, A. K. W. and Harris, F. C. (1998). Construction Productivity Management. The Chattered Institute of Building, Addison: Wesley Longman Limited, pp. 1 - 290.

[51]. Sanders, S. R. and Thompson, P. J. (1999). Project-specific Employee Incentives. Construction Industry Institute Research Report, 140(11), 221-223.

[52]. Saka, N. and Ajayi, O. M. (2010). A Comparative Assessment of Incentive Scheme between Indigenous and Multinational Construction Contractors in Nigeria. In Egbu, C. (Ed.) Proceedings of 26th Annual ARCOM Conference, 6-8 September, Leeds, UK, Association of Researchers in Construction Management, 583-591. 
International Journal of Advances in Scientific Research and Engineering (ijasre), Vol 6 (8), August -2020

[53]. Laufer, A. and Moore, B. E. (1983). Attitudes Toward Productivity Pay Programmes. Journal of Construction Engineering and Management, 109(1), 89-101. https://doi.org/10.1061/(ASCE)0733-9364(1983)109:1(89)

[54]. Olomolaiye, P. O. (1990). An Evaluation of the Relationship between Bricklayers' Motivation and Productivity. Construction Management and Economics, 8(3), 301-313.

https://doi.org/10.1080/01446199000000025

[55]. Sauer, S. J., Rodgers, M. and Becker, W. J., (2018). The Effects of Goals and Pay Structure on Managerial Reporting Dishonesty. Journal of Accounting, Ethics and Public Policy, 19(3), 377-418.

[56]. Poon, C. S. and Ng, L. H. (1999). The Use of Modern Building Technologies for Waste Minimisation in Hong Kong, In C. S. Poon and X. Y. Li (eds.), Proceeding of International Conference on Urban Pollution Control Technology, The Hong Kong Polytechnic University, Hong Kong, 413-419.

[57]. Pilcher, R. (1992). Principles of Construction Management, $3^{\text {rd }}$ ed., McGraw-Hill, New York, p. 89.

[58]. Adewuyi, T. O. (2012), Construction Material Waste Planning and Control Techniques on Building Sites in South-South of Nigeria. Ph.D. Thesis, Department of Building, Faculty of Environmental Studies, University of Uyo, Uyo, Nigeria.

[59]. Tsai, W. H., Lin, S. J., Lee, Y. F., Chang, Y. C., and Hsu, J. L. (2013). Construction Method Selection for Green Building Projects to Improve Environmental Sustainability by Using an MCDM Approach. Journal of Environmental Planning and Management, 56(10), 1487-1510. http://doi.org/10.1080/09640568.2012.731385.

[60]. Idoro, G. I. (2011). Effect of Mechanisation on Occupational Health and Safety Performance in the Nigerian Construction Industry. Journal of Construction in Developing Countries, 16(2): 27-45.

http://web.usm.my/jcdc/vol16_2_2011/ART2_jcdc16-2.pdf

[61]. Anotonio, R. S., Isabel, O. M., Gabriel, P. S. J. and Angel, U. C. (2013). A Proposal for Improving Safety in Construction Projects by Strengthening Coordinators' Competencies in Health and Safety Issues. Safety Science, 54, 92-103. https://doi.org/10.1016/j.ssci.2012.12.004

[62]. Wong, R. Castater, N. and Payne, B. (2015). A Canonical Correlation Approach to Investigate the Determinants of Investment Safety. Journal of the Southwestern Society of Economists; Beaumont, 42, 29-43.

[63]. Nanaware, M. R. and Saharkar, U. R. (2017). Application of Inventory Control Technique in Construction. International Journal of Engineering Research and General Science, 5(4), 49-54.

[64]. Jabar, I. L., Ismail, F., and Aziz, A. R. A. (2018). Stakeholder's Perception of Industrialized Building System (IBS) Implementation. Asian Journal of Behavioural Studies (AjBeS), 3(10), 159-166. http://dx.doi.org/10.21834/ajbes.v3i10.90

[65]. Alinaitwe, H. M., Mwakali, J. and Hansson, B. (2006). Assessing the Degree of Industrialisation in Construction: A case of Uganda. Journal of Civil Engineering and Management, 12(3): 221-229. http://dx.doi.org/10.1080/13923730.2006.9636396

[66]. Wong, R. W. M., Hao, J. J. L. and Ho, C. M. F. (2005). Prefabricated Building Construction Systems Adopted in Hong Kong. http://personal.cityu.edu.hk/ bswmwong/pp/PrefabricatedConstruction.pdf

[67]. Sherry, A. and Henson. R. K. (2005). Conducting and Interpreting Canonical Correlation Analysis in Personality Research: a user-friendly Primer. Journal of Personality Assessment, 84(1), 37-48.

[68]. Pallant, J. (2007). SPSS Survival Manual - A Step by Step Guide to Data Analysis using SPSS for Windows. 3rd ed., England: McGraw Hill, Open University Press, pp. 1 -311. 


\section{APPENDIX}

The default error term in MANOVA has been changed from WITHIN CELLS to

WITHIN+RESIDUAL. Note that these are the same for all full factorial designs.

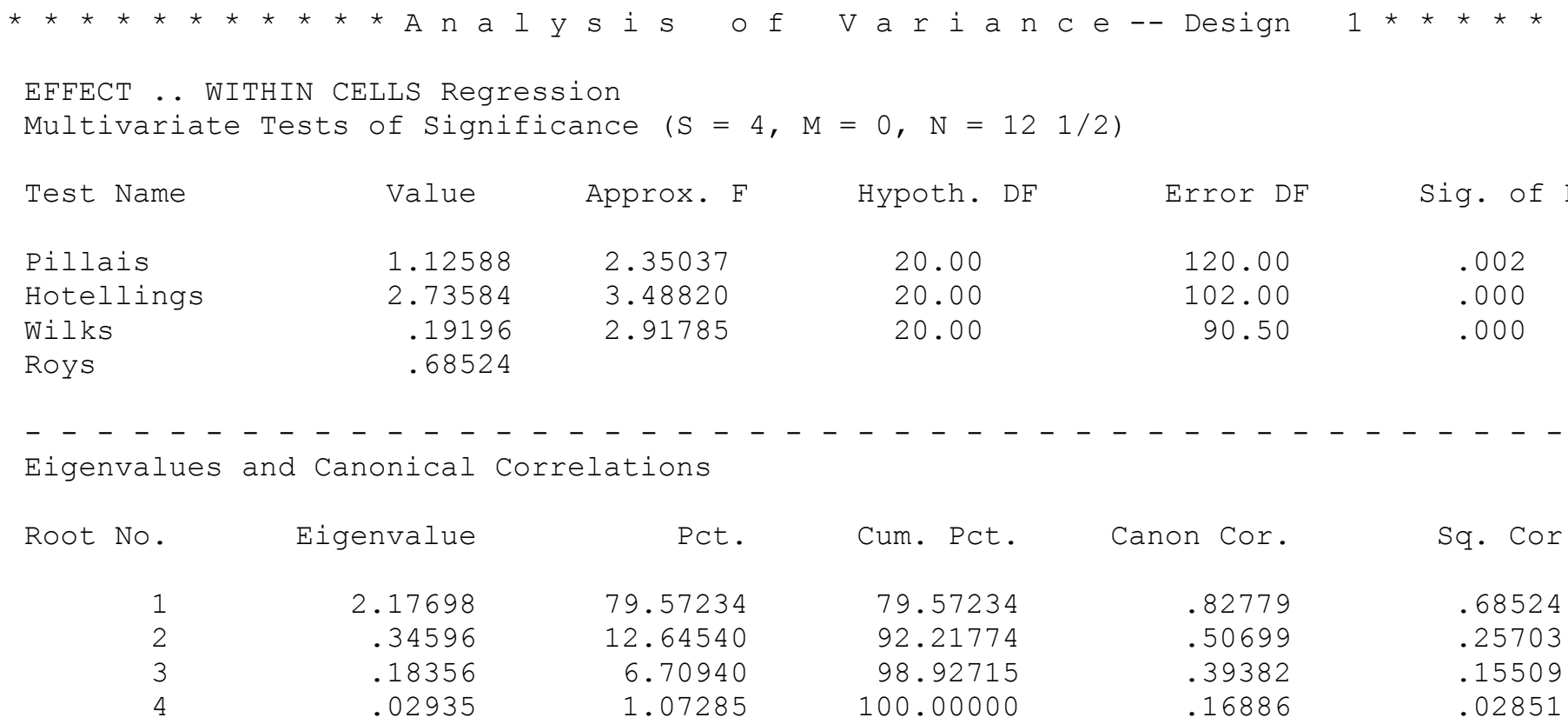

Dimension Reduction Analysis

\begin{tabular}{lrrrrr} 
Roots & Wilks L. & \multicolumn{1}{c}{ F } & Hypoth. DF & Error DF & Sig. of F \\
1 TO 4 & .19196 & 2.91785 & 20.00 & 90.50 & .000 \\
2 TO & .60984 & 1.27387 & 12.00 & 74.37 & .252 \\
3 TO 4 & .82082 & 1.00307 & 6.00 & 58.00 & .432 \\
4 TO 4 & .97149 & .44027 & 2.00 & 30.00 & .648
\end{tabular}

EFFECT .. WITHIN CELLS Regression (Cont.)

Univariate F-tests with $(5,30)$ D. F.

Variable Sq. Mul. R Adj. R-sq. Hypoth. MS Error MS F $\quad$ Sig. of F

$\begin{array}{ccccccc}\text { MM } & .55014 & .47516 & .05165 & .00704 & 7.33738 & .000 \\ \text { MC } & .36668 & .26113 & .51183 & .14734 & 3.47387 & .014 \\ \text { IN } & .44019 & .34689 & .17458 & .03700 & 4.71791 & .003 \\ \text { PR } & .14250 & .00000 & .09043 & .09070 & .99710 & .436\end{array}$

Standardized canonical coefficients for DEPENDENT variables Function No.

Variable

1

2

3

4

$\begin{array}{lrrrr}\text { MM } & -.47029 & .74721 & .84242 & .72923 \\ \text { MC } & -.44960 & -1.45997 & .59006 & -.53828 \\ \text { IN } & -.18475 & .79602 & -1.33273 & -.50918 \\ \text { PR } & .50914 & .73395 & .39576 & -.52594\end{array}$


Correlations between DEPENDENT and canonical variables Function No.

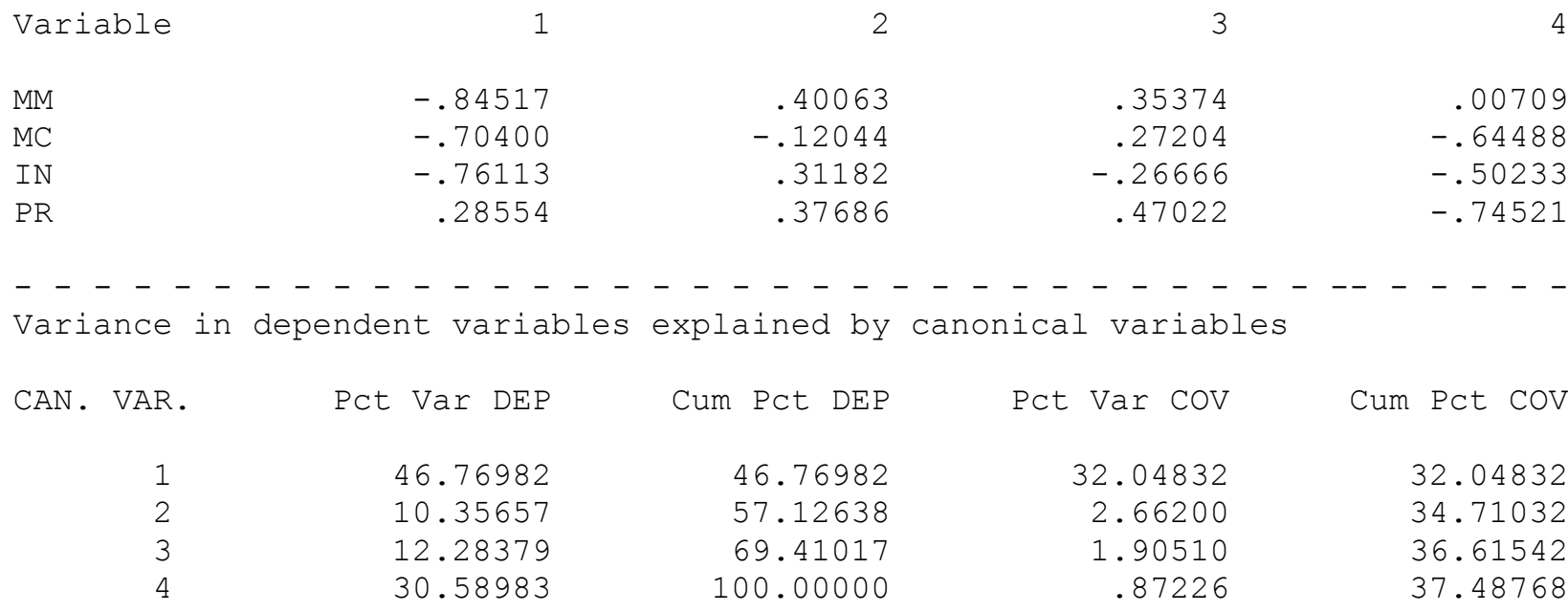

Standardized canonical coefficients for COVARIATES

CAN. VAR.

COVARIATE

$\begin{array}{lrrrr}\text { Conc } & .63988 & -1.18057 & -.13227 & 1.18336 \\ \text { Blk } & .07101 & .01639 & .20957 & -.21251 \\ \text { Reinf } & .30139 & -.54577 & .76045 & -.38717 \\ \text { Timb } & -.19863 & 1.67467 & .46915 & -.19468 \\ \text { Tiles } & .43347 & .22758 & -1.04722 & -.50224\end{array}$

Correlations between COVARIATES and canonical variables CAN. VAR.

Covariate

Conc

$\mathrm{Blk}$

Reinf

Timb

Tiles
1

.81053

.68400

.68300

.67415

.83249
2

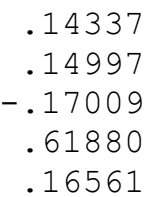

4

.55920

$-.20830$

$-.47565$

.28603

$-.32958$

Variance in covariates explained by canonical variables

CAN. VAR .

Pct Var DEP

$$
\begin{array}{r}
37.53466 \\
2.47945 \\
1.92432 \\
.44070
\end{array}
$$

Cum Pct DEP

37.53466

40.01411

41.93843

42.37914
Pct Var COV

54.77632

9.64634

12.40773

15.45529
Cum Pct COV

54.77632

64.42266

76.83039

92.28568 